\title{
TRANSDISCIPLINARIDADE: O DESAFIO DE INOVAR
}

\section{Pesquisa transdisciplinar reafirma desigualdade socioeconômica, baixo nível de escolaridade dos pais e má qualidade do ensino como fatores de evasão e repetência escolar}

INSTRUÍ-VOS porque temos necessidade de toda a nossa inteligência; agitaivos, porque teremos necessidade de todo o nosso entusiasmo; ORGANIZAI-VOS porque teremos necessidade de toda a nossa força.

\section{A. Gramsci}

Este trabalho resultou de um exercício de investigação realizado por um grupo de professores pós-graduandos da disciplina de Pediatria Social ${ }^{1}$. As atividades de ensino e pesquisa desenvolvidas nesta disciplina suscitaram discussões que envolveram um grupo multidisciplinar de professores, pediatras, enfermeiros, sociólogos, psicólogos e alunos $^{2}$. Uma outra condição que também favoreceu e encorajou profissionais da saúde e da educação a trabalharem juntos foi a proposta do Núcleo de Estudos da Criança e do Adolescente - NECA e seu acervo que conta com trabalhos que deram importante subsídio a este artigo ${ }^{3}$.
O projeto denominado Estudo Epidemiológico-Social Longitudinal da Saúde da Criança de uma coorte (população) em três momentos - ao nascer, na idade escolar e aos 18 anos $^{4}$ - serviu como pano de fundo e despertou o interesse em avaliar a escolaridade dos meninos em relação à escolaridade

\section{OS AUTORES}

\section{Maria Inês F. Miranda}

Professora na Enfermagem da Universidade Federal de Rondônia.

\section{Marisa R. Barbieri}

Professora Doutora do Departamento de Psicologia e Educação e do Laboratório de Ensino de Ciências da Faculdade de Filosofia, Ciências e Letras de Ribeirão Preto da USP.

\section{Leris S. B. Haeffner}

Professora de Pediatria da Universidade Federal de Santa Maria - RS.

\section{Carlos H. F. Tavares}

Professor de Pediatria na Universidade Federal de Alagoas.

\section{Marco Antônio Barbieri}

Professor Doutor da Faculdade de Medicina de Ribeirão Preto da USP.

1. Disciplina oferecida pelo Programa de Pós-Graduação do Departamento de Puericultura e Pediatria da Faculdade de Medicina de Ribeirão Preto da USP, coordenada pelo Prof. Dr. Marco Antônio Barbieri.

2. Parte do resultado desse intenso processo está em: HAEFFNER, L. S. B., MIRANDA, M. I. F., TAVARES, C. H. F., BETTIOL, H., BARBIERI, M. R., BARBIERI, M. A. Influências socioculturais na escolaridade de conscritos - Ribeirão Preto - SP - Brasil. Monografia apresentada ao Programa de Pós-Graduação do Departamento de Pediatria da FMRP-USP, 1997, como requisito para conclusão da disciplina Pediatria Social.

3. BARBIERI, M. R. et. al. Nucleus for the study of children and adolescents (Núcleo de estudo da criança e do adolescente). Comunicação apresentada e publicada nos Anais da Biennale de l'Education et de la Formation. Paris: Sorbonne, 1994. p. 36.

4. O projeto inicial Saúde Perinatal em Ribeirão Preto, sob a coordenação do Prof. Dr. Marco Antônio Barbieri, coletou dados de $98 \%$ dos recém-nascidos no período de um ano (1978/79) na cidade de Ribeirão Preto. Estes mesmos indivíduos foram reavaliados na escola e aos 18 anos de idade. Os dados aos 18 anos foram obtidos das fichas do alistamento militar, onde foram localizados 2.847 conscritos pertencentes ao projeto inicial e, destes, 1.336 responderam a uma entrevista. 
de seus pais. Este primeiro interesse pela escolaridade deu lugar ao projeto interdisciplinar que, embora não seja uma prática comum, foi desenvolvido pelos professores alunos da pós-graduação. Estudar escolaridade envolve questões sociais, econômicas e culturais, ficando clara a necessidade de uma resposta inter e transdisciplinar.

Morin prefere o conceito de transdisciplinaridade ao de interdisciplinaridade, porque este seria uma forma disfarçada de controle sobre as disciplinas. "Sabemos cada vez mais que as disciplinas se fecham e não se comunicam umas com as outras. Os fenômenos são cada vez mais fragmentados, e não se consegue conceber a sua unidade. É por isso que se diz cada vez mais: 'Façamos interdisciplinaridade'. Mas a interdisciplinaridade controla tanto as disciplinas como a $\mathrm{ONU}$ controla as nações. Cada disciplina pretende primeiro fazer reconhecer sua soberania territorial, e, à custa de algumas magras trocas, as fronteiras confirmam-se em vez de se desmoronar. Portanto, é preciso ir além, e aqui aparece o termo "Transdisciplinaridade""s.

No Brasil, em 1990, as estatísticas relatavam que mais da metade da população infanto-juvenil $(58,2 \%)$ era pobre 6 . A situação de pobreza tem efeito direto sobre a vida das crianças nos seus aspectos mais fundamentais: saúde, nutrição e educação. A complexidade desta realidade levou à transdisciplinaridade, considerando que a necessidade da mesma não provém apenas das deficiências do conhecimento científico ou da organização histórica de seu fomento, mas sobretudo da realidade como tal ${ }^{7}$. Segundo Demo, para a construção da prática transdisciplinar exige-se grande cautela: “a) somente pode ser tomada como equipe transdisciplinar aquela composta por especialistas diversificados, de preferência oriundos de áreas 'opostas';

b) para funcionar, uma equipe transdisciplinar não pode apenas compor competências diversas, mas sobretudo orquestrar os esforços de modo convergente; não se trata de justapor conhecimentos, mas de integrá-los num tecido único;

c) a arte de tecer a muitas mãos pode ser auxiliada, no início, pela tática de exigir de cada uma o tecido próprio, para somente depois integrá-los; no caso ideal, é mais integrado o que já nasce integrado (...)"».

$\mathrm{Na}$ atenção integral ao desenvolvimento da criança, o conjunto de ações necessárias abrange diferentes áreas do conhecimento. Isto significa que deve haver planejamento e supervisão de um trabalho coletivo de natureza multiprofissional. As ações coletivas na área da educação e da saúde podem e devem ser feitas por equipe multiprofissional com formação multidisciplinar.

A prática multiprofissional deve ser construída de tal forma que cada um seja capaz de ter uma concepção integral do indivíduo, sabendo identificar quando há realmente necessidade de atuação conjunta com profissional de outra área. Os especialistas de uma só área não conseguem responder a todas as perguntas. A experiência em reunir os iguais, de uma mesma área, não alcançou os resultados esperados - Institutos, Departamentos etc. -, modelo de administração que são as atuais estruturas das universida-

5. MORIN, E. Ciência com consciência. Rio de Janeiro: Bertrand Brasil, 1996. p. 135.

6. IBGE. Crianças e adolescentes - Indicadores sociais. Rio de Janeiro, v. 4, 1992. p. 1-159.

7. COHN, N. Cosmos, caos e o mundo que virá. São Paulo: Companhia das Letras, 1996.

8. DEMO, P. Conhecimento moderno - Sobre ética e intervenção do conhecimento. Petrópolis: Vozes, 1997. p. $112-113$. 
des. Hoje o pressuposto para o aprofundamento nas questões educacionais exige uma resposta articulada, a fim de fundamentar o conhecimento do professor. A proposta multidisciplinar leva a um olhar e um agir na tentativa de responder a estas necessidades. Não apresenta soluções mágicas. Depende de uma construção conjunta, porque afinal o aluno está em classe e nessa classe atuam professores de várias especialidades.

\section{TRABALHO MULTIPROFISSIONAL}

Hoje, deve-se buscar definições atualizadas das condições de saúde e educação, para um estudo em Pediatria Social, tendo em vista a saúde da criança. É preciso reafirmar que o tema exige considerações e análises que levem em conta, entre outras, as desigualdades sociais e econômicas, a pluralidade (diferença) cultural e as diversidades biológicas. É com estas preocupações que se coloca o objeto de estudo - a escolaridade das crianças - na relação herança/ meio como um processo de complementaridade/oposição, para melhor compreender a visão epidemiológica e individual.

Este trabalho lida com termos mais relacionados ao campo de epidemiologia, referido à saúde da criança, no entanto interessa a todos os profissionais que com ela trabalham.

Dentro da perspectiva mais epidemiológica, utilizada em trabalhos de populações, foi realizado um estudo através do delineamento longitudinal, ou seja, que pôde acompanhar ao longo de 18 anos um grupo de recém-nascidos da cidade de Ribeirão Preto-SP. Levaram-se em conta diferenças socioeconômicas em eventos como mortalidade, crescimento físico e escolaridade. Segundo Fox ${ }^{9}$, a importância do estudo longitudinal está justamente na possibilidade de se conhecer a mobilidade social, com a vantagem de que esse tipo de delineamento provoca potenciação da relação causa-efeito.

Trabalhos têm demonstrado a importância da escolaridade nas condições de saúde e de cidadania ${ }^{10}$. "Como a escola está sempre inserida numa dada sociedade, muito se tem escrito a respeito das relações desta com aquela. A escola sempre e só reproduz, em sua ação, as características da sociedade na qual esteja inserida; sempre melhora a sociedade, pois a transforma positivamente; é um lugar de luta, de vida e pode reproduzi-la ou não, na dependência da ação concreta nela desenvolvida" 11 .

Os autores, preocupados com esta realidade, buscaram, com o presente trabalho, uma visão coletiva e multiprofissional das relações da saúde ligadas à educação, ampliando a atividade geralmente individualizada/individualizante do processo de formação do pós-graduando (teses, dissertações, monografias), além de procurar responder algumas questões em relação à escolaridade de pais e filhos, tais como a mobilidade educacional ascendente ou não - fundamental para a ascensão social ${ }^{12}$. Por outro lado, questões que julgamos fundamentais como: qual a história desta escolaridade e qual a qualidade dessa escolaridade?, ficam na de-

9. FOX, A. J. Longitudinal studies based on vital registration records (Estudo longitudinal baseado em registros de nascimento). Epidem. Santé Publ. França, n. 37, 1989. p. 443-448.

10. BRASIL. MINISTÉRIO DA EDUCAÇÃO E DO DESPORTO. Parâmetros Curriculares Nacionais. v. 1, Brasília, 1997. p. 33-34.

11. SILVA, J. M. A criança, a educação e a saúde: a educação escolar. In: Saúde escolar: A criança, a vida e a escola. São Paulo: Sarvier, 1994. p. 19-22.

12. GALAZI, J. Filho de pai sem instrução avança mais na escola que os outros. O Estado de S. Paulo. 17 de dezembro de 1997. p. A-10. 
pendência de uma interação maior com os que realmente vivem os problemas da escolaridade brasileira, os professores.

Os limites do conhecimento e os próprios limites dos métodos científicos são considerados como a origem da transdisciplinaridade. Buscam-se na multiprofissionalidade e transdisciplinaridade os outros saberes que justifiquem e expliquem as transformações da sociedade e, claro, do "homem como ser social" 13 . Sentiu-se a necessidade de estudos transdisciplinares devido à urgência em superar os malefícios claros da compartimentalização do conhecimento, prática comum nas instituições universitárias e no ensino em geral. A departamentalização que serviu para uma busca de autonomia acadêmica e uma forma de gestão mais democrática, colaborou também para a reclusão departamental, que acabou favorecendo a especialização e levando a: "cada departamento, a rigor, se basta"14. Este alerta nos foi possível devido à integração com o NECA e à abertura da disciplina Pediatria Social a profissionais de várias formações dentro da área de Saúde e Educação.

O NECA tem, entre os seus propósitos, interesses em estreita relação com o meio ambiente. Entre elas se destacam: a educação escolar e o acesso e permanência na escola, a formação continuada dos professores, a relação saúde/aprendizagem, o processo de crescimento da criança e do adolescente e a compreensão desse processo.
Nesta trajetória do núcleo está embutida a intencionalidade de melhoria da qualidade do serviço público de Educação e Saúde, utilizando para tal o trânsito da equipe permanente do Laboratório de Ensino de Ciências - LEC e a assessoria dos especialistas nas áreas de Educação e Saúde, considerando que ambas utilizam o mesmo objeto/sujeito ${ }^{15}$.

\section{ESCOLARIDADE E NÍVEL ECONÔMICO}

Embora a previsão para a década de 90 não tenha sido muito alentadora para o Brasil, observa-se, com este estudo, que Ribeirão Preto-SP apresenta algumas características peculiares que a diferenciam tanto no aspecto da divisão econômica quanto no nível de escolaridade. Tendo como parâmetro a proposta descrita por Goldani 16 e formulada no NECA, foram classificados como pobres em Ribeirão Preto-SP 39,6\% (no Brasil 58,2\%) ${ }^{17}$ de uma amostra de 2.838 conscritos (recrutados pelo serviço militar) pertencentes a coorte de recém-nascidos de Ribeirão Preto 1978/79. Com relação ao nível de escolaridade, $60,6 \%$ dos conscritos da coorte concluíram o primeiro grau, $47,1 \%$ dos pais e $47,3 \%$ das mães. Fica claro uma mobilidade ascendente do nível de escolaridade dos filhos com relação ao nível de escolaridade dos pais.

13. MINAYO, M. C. S. O desafio do conhecimento - Pesquisa qualitativa em Saúde. 4. ed. São Paulo: Hucitec/ Brasco,1996.

14. SEIBLITZ, Z. Três dimensões da noção de interdisciplinaridade. Debates Sociais - CBCISS (Co-edição Departamento Serviço Social da PUC/Rio), ano XXX, $1^{\circ}$ e $2^{\circ}$ semestre, n. 54/55, 1995. p. 55-78.

15. CARVAlHO, C. P. et. al. Dimensão social do meio ambiente. Comunicação \& Educação. São Paulo: CCA-ECAUSP/Moderna, n. 7, set./dez. 1996. p. 21-25.

16. Classificação de classe social, bairro pobre: $70 \%$ ou mais dos chefes de familia têm rendimento inferior a cinco salários mínimos; bairro médio-baixo: 45 a $70 \%$ dos chefes de família com rendimento inferior a cinco salários mínimos; bairro médio-alto: 20 a $45 \%$ dos chefes de família com rendimento inferior a cinco salários mínimos; e bairro rico: menos de $20 \%$ dos chefes de família com rendimento inferior a cinco salários mínimos. Para melhor análise foi feita classificação em dois grupos: pobre + médio-baixo $(\mathrm{P})$ e rica + médio-alto $(\mathrm{R}) ; 1997$.

17. IBGE. Crianças e adolescentes - Indicadores sociais. op. cit. 
A constatação de que a educação está ligada ao nível econômico foi reafirmada quando se dividiram os conscritos em grupos. Observou-se que $21,3 \%$ do grupo R completaram o segundo grau e $15,3 \%$ estavam no curso superior, enquanto que os do grupo $P, 9,8 \%$ e $3,2 \%$ estavam nas situações respectivas. Por outro lado, todos os analfabetos $(0,1 \%)$ estavam no grupo P. Do total de conscritos do grupo R, $48 \%$ tinham distorção série/idade e nos do grupo $\mathrm{P}$ o percentual foi de $\mathbf{7 5 , 1 \%}$. Estes resultados evidenciam as diferenças quanto ao nível de escolaridade, dependendo da classe socioeconômica a que o indivíduo pertence.

\section{MÉDIA DE ESCOLARIDADE}

"Essa desigualdade é nossa grande mazela" 18 , no documento Indicadores sobre crianças e adolescentes no Brasil 19911996, o IBGE em parceria com o Fundo das Nações Unidas de Amparo à Infância UNICEF mostra um Brasil cheio de senões. $\mathrm{O}$ aumento do número de crianças na escola foi prejudicado pelos altos índices de evasão e repetência escolares. Algum avanço foi detectado, no entanto, em relação à escolaridade. Na faixa de 10 a 14 anos, o índice cresceu de $84,2 \%$ para $89,8 \%$.

Enquanto a média de escolaridade no Brasil é quatro anos, a média de escolaridade dos conscritos de Ribeirão Preto foi nove anos (correspondendo à primeira série do Ensino Médio) e, para ambos, a média de escolaridade dos pais foi cinco anos (quinta série do Ensino Fundamental). O analfabetismo, situação pouco admissível às portas do terceiro milênio, atinge no Brasil a cifra de $36,3 \%$ e na amostra estudada foi encontrado um percentual de $0,1 \%$ entre os conscritos, $2,2 \%$ entre os seus pais e $4,2 \%$ entre as suas mães.

Com relação a chegar à série final do ensino básico, países como o México $(71,4 \%)$, Uruguai $(85,9 \%)$ e Venezuela $(73,1 \%)$, considerados do mesmo grupo econômico que o Brasil e com sistemas educacionais de seis anos, conseguem percentuais mais altos que os brasileiros e, inclusive, que os de Ribeirão Preto (60,6\% para os conscritos, $47,1 \%$ para os pais dos conscritos e $47,3 \%$ para as mães dos conscritos).

\section{ESCOLARIDADE DOS PAIS}

Um dos objetivos do trabalho foi comparar a escolaridade dos conscritos em relação à escolaridade de seus pais; a hipótese era a de que ocorreu mobilidade ascendente no grau de escolaridade dos conscritos. Considerando como maior escolaridade a frequiência a uma série a mais que seus pais, verificou-se que $61,8 \%$ dos filhos têm escolaridade superior à de seus pais e $58 \%$ à de suas mães.

É evidente o fato de que a partir da quinta série do Ensino Fundamental a diferença passa a ser mais importante, pois um número significativo de pais só cursou até a quarta série. Observou-se que $53,5 \%$ dos filhos de pais que tinham o Ensino Fundamental completo ou incompleto, passaram para o Ensino Médio e 3,8\% passaram para o Ensino Superior; dos pais que tinham o Ensino Médio completo ou incompleto, $69,1 \%$ dos filhos estavam no Ensino Médio e $16,2 \%$ já estavam no curso Superior; e dos pais que tinham curso Superior completo ou incompleto, 30,9\% dos filhos já estavam no curso Superior. A escolaridade dos pais pode ser um determinante na escolaridade dos 
filhos, na medida em que os filhos de pais com maior escolaridade tiveram menor dificuldade de passar para os níveis mais elevados no grau escolar.

\section{ENSINO PÚBLICO VERSUS ENSINO PRIVADO}

Outro ponto que despertou muito interesse foi o tipo de escola freqüentada pelos conscritos durante a sua vida estudantil. Chamou a atenção o grande número que freqüenta a escola pública, demonstrando a sua importância no sistema educacional. É esperado que os pertencentes às classes sociais mais altas optem menos pela escola pública (exclusivamente $31,9 \%$ ), quando comparados com os conscritos de classes mais baixas, em que $85,2 \%$ freqüentaram exclusivamente a escola pública. Esta diferença no percentual de uso das escolas públicas e privadas nas diferentes divisões econômicas da população evidencia a procura das classes mais ricas por escolas privadas, na hipótese de que estas ofereçam melhores condições de ensino que as escolas públicas, que carecem de políticas públicas sociais adequadas. Esta procura, provavelmente, tem como objetivo a transposição da barreira que existe no sistema brasileiro para se chegar ao Ensino Superior. A mudança no tipo de escola ocorreu com maior frequeiência da escola pública para a privada nos últimos anos do Ensino Médio, o que deve estar relacionado com o preparo para o vestibular.

\section{EVASÃO VERSUS REPETÊNCIA}

Com 18 anos de idade, mais de 50\% da amostra de ambos os grupos ainda fre- qüentam a escola, mas é evidente a maior taxa do grupo com melhores condições. $\mathrm{O}$ importante, neste sentido, não é só igualar as possibilidades de acesso à escola como também adequar essa oferta às condições de aprendizagem das populações, principalmente as excluídas, de modo que se sintam atraídas e permaneçam o tempo adequado na experiência de aprendizagem. Segundo o capítulo sobre $A$ evasão escolar ${ }^{19}$, o significado mais imediato da evasão escolar é sair do sistema escolar formal e com isso impossibilitar, no futuro, a participação plena na comunidade e na sociedade, gerando maior desigualdade para quem o experimenta, e um alto custo social presente e futuro para o conjunto da sociedade.

A saída da escola sem o Ensino Médio completo é causada por diversos fatores. Estão entre eles a repetência, a falta de estímulos do próprio sistema escolar e da sociedade e a necessidade de trabalhar - como forma de aumentar a renda doméstica. Este último, considerado como o maior fator exógeno, ou seja, externo ao próprio sistema escolar, foi verificado neste estudo em somente $13,2 \%$ dos conscritos que deixaram de estudar.

Importante é ressaltar que o período crítico para o abandono da escola está nas últimas séries do Ensino Fundamental e que os alunos que abandonaram a escola conseguem concluir em média a sexta série, diferentemente da média nacional de abandono que é de 3,7 séries, ou seja, entre a terceira e a quarta séries do Ensino Fundamental, menos que a quantidade considerada mínima para tornar irreversível e duradoura a alfabetização. 


\section{EVASÃO VERSUS DISTORÇÃO SÉRIE/IDADE}

O sistema educacional estabelece a idade de sete anos para o início da escolarização e isso define uma correspondência entre série/idade na vida escolar. Várias causas contribuem para a inadequação série/idade, entre elas estão a entrada tardia na escola e a repetência. A taxa de $58,2 \%$ de distorção série/idade observada neste estudo, embora elevada, é menor do que a taxa brasileira de $80 \%$; do que a taxa da região Nordeste de $92 \%$; e do que a própria taxa da região Sudeste de $76 \%$. O fato está relacionado com as condições socioeconômicas, de escolaridade dos pais $(89,4 \%$ dos conscritos, cujos pais têm curso superior completo, não têm distorção série/idade) e, principalmente, do tipo de ensino fornecido, ensino esse que empurra o aluno para fora da escola.

Estudar a escolaridade dos jovens conscritos pertencentes a coorte de recémnascidos de Ribeirão Preto (78/79), de uma forma multiprofissional e transdisciplinar, e compará-la com a escolaridade de seus pais nos deu a oportunidade de constatar a complexidade que abrange as questões das políticas sociais no Brasil. A educação só suscitava e suscita preocupação, quando interesses políticos, econômicos e até individuais de uma parcela específica da população (elite) estão em jogo.

Verificou-se que Ribeirão Preto, devido às suas peculiaridades econômicas, sociais e culturais, apresenta uma média de séries concluídas duas vezes maior que a brasileira. Mesmo com esses índices, que mostram que os conscritos tiveram melho- res oportunidades de acesso à escola do que seus pais, a conclusão do Ensino Fundamental para todos ainda enfrenta dificuldades para se tornar realidade.

A evasão escolar, enquanto vista exclusivamente como conseqüência de baixas condições socioeconômicas e, em virtude disto, a necessidade do trabalho infantil para aumento da renda familiar, neste trabalho não se confirmou, pois a maioria que deixou a escola o fez por outros motivos. Outro aspecto que merece atenção, embora não tenha sido objeto deste trabalho, é a afirmação "faltou comida, o aluno é burro", que vem associada à medicalização do fracasso esco$\operatorname{lar}^{20}$, resultado da avaliação inadequada dos profissionais da saúde e especialmente do médico que, devido à sua posição hegemônica, sente-se autorizado a discorrer sobre diferentes temas: família, educação, prostituição, objetivando a higienização e a saúde do povo. A evasão, provavelmente, seja causada pelas consecutivas repetências, o que mostra a necessidade de uma reformulação no Sistema de Ensino Brasileiro, "a pedagogia da repetência"21.

Pais, educadores e outras pessoas precisam preparar as crianças para serem bem-sucedidas no mundo de amanhã, proporcionando a elas não somente competência técnica mas aptidões e ética interpessoais com compromisso político. $\mathrm{Na}$ escola, como um espaço de formação e informação, a aprendizagem de conteúdos deveria necessariamente favorecer a inserção do aluno no dia-a-dia das questões sociais marcantes em um universo cultural maior. É preciso garantir o acesso aos saberes, pois estes saberes são os instrumentos para o desenvolvimento, para a socialização, para o exercício da cidadania.

20. COLLARES, C. A. L. Ajudando a desmistificar o fracasso escolar. In: Preconceito no cotidiano escolar - Ensino e medicalização. São Paulo/Campinas: Cortez/ Edunicamp, 1996. p. 24-28.

21. RIBEIRO, S. C. A pedagogia da repetência. Estudos em Avaliação Educacional. São Paulo, 1995. p. $73-85$ (mimeo.) 
Mais do que a simples expansão quantitativa da oferta, ficou evidente a importância que se deveria dar, no Brasil, a definições específicas no sentido de se aumentar os níveis de permanência do aluno no sistema, uma vez que o aumento do número de crianças nas escolas tem sido prejudicado pelo alto índice de evasão e repetência escolares $^{22}$. É importante colocar as crianças na escola, mas é também importante prover meios que as mantenham lá, por período suficiente, para que a aprendizagem se torne irreversível e duradoura.

Os brasileiros menores de 18 anos representam quase $40 \%$ da população, mas recebem apenas $12,4 \%$ dos gastos sociais. Os custos sociais dos adultos são superiores aos das crianças. Nos gastos com adultos foram contabilizados os custos com a previdência, com o ensino superior e com a saúde curativa (muito mais cara para adultos). Manuel Bovinich ressalta que esse desequilíbrio poderia ser reduzido, racionalizando-se recursos, "mas mexer nessa situação é uma questão política, que envolve corporativismo dos próprios professores e do governo"23.

$\mathrm{O}$ fracasso escolar generalizado, tomado como natural, fazendo da escola mais que tudo um sistema de seleção e, principalmente, levando-se em conta que tal seletividade se volta contra as camadas mais pobres da população, resulta que a educação brasileira ainda não favorece a cidadania.

A nova Lei de Diretrizes e Bases e, recentemente, o lançamento dos Novos Parâmetros Curriculares Nacionais trazem novas discussões, principalmente em relação ao comportamento do professor durante as aulas. "Eles terão que inserir nas disciplinas gerais os conceitos de ética, saúde, meio ambiente, orientação sexual e pluralidade cultural" 24 (temas transversais). Fica claríssimo que a formação dos professores deverá ser transdisciplinar, o que ainda não é a prática nas instituições de Ensino Superior brasileiras.

\section{AQUISIÇÃO DE NOVAS COMPETÊNCIAS}

Desde a construção dos primeiros computadores, na metade deste século, novas relações entre conhecimento e trabalho começaram a ser delineadas. Um dos seus efeitos é a exigência de um reequacionamento do papel da educação no mundo contemporâneo, que coloca para a escola um horizonte mais amplo e diversificado (pluridisciplinar) do que aquele que, até poucas décadas atrás, orientava a concepção e construção dos projetos educacionais.

Não basta visar à capacitação dos estudantes para futuras habilitações em termos das especializações tradicionais (multiespecialidade), mas antes trata-se de ter em vista a formação dos estudantes em termos de sua capacitação para a aquisição e o desenvolvimento de novas competências, em função de novos saberes (transdisciplinares) que se produzem e demandam um novo tipo de profissional, preparado para poder lidar com novas tecnologias e linguagens capazes de responder a novos ritmos e processos. É preciso "aprender a aprender" 25.

Toda tecnologia existente - computadores, Internet, teleconferências - numa sala de aula, sem um bom professor, torna-se mera sucata. "A escola será melhor se tiver computadores para o uso dos alunos, com a 
condição de que tenha bons professores, de preferência portadores de conhecimentos sobre o uso dessas novas ferramentas"26.

Alfredo Bosi sintetiza o que sentimos: “(....) constato o primado das coisas sobre as pessoas. Computadores aos milhares sem professores prezados e estimulados são sucata virtual. Livros didáticos sem mestres que os leiam e os interpretem com garra e entusiasmo são pilhas de papéis destinados ao lixo do esquecimento. Quanto às avaliações severas prometidas (tremam os relapsos afundados nos seus pingues proventos!),

Resumo: $\mathrm{O}$ presente trabalho tem por objetivo relatar resultados analisados por atores multiprofissionais que investigaram dados sobre o nível de escolaridade de uma amostra de jovens nascidos entre 1978/79 em Ribeirão Preto, São Paulo, Brasil, relacionando estes dados à complexa realidade socioeconômica do país, à escolaridade dos pais destes alunos, bem como aos problemas de evasão escolar. Isto foi possível graças ao programa da Disciplina de Pediatria Social (FMRP-USP), permitindo a articulação com o propósito do Núcleo de Estudo da Criança e do Adolescente e o Laboratório de Ensino de Ciências (FFCL-USP).

Palavras-chave: escolaridade, conscritos, transdisciplinaridade, repetência, evasão escolar supõem um longo tempo de experiência em condições humanas de trabalho. As pessoas, quando respeitadas no seu ofício, produzem sentido e valor. Com ou sem as coisas. Mas as coisas sem as pessoas são letra morta. Preferir coisas a pessoas não é realismo. É apenas conformismo"27.

Segura o livro, ele é uma arma tens que assumir o comando Bertold Brecht (1998- 100 anos de nascimento)

\begin{abstract}
This article aims at reporting on results analyzed by multi-professional actors who investigate data on the academic levels achieved by a sample of young people born between 1978/79 in the city of Ribeirão Preto, São Paulo, Brazil. These data were related to the complex socioeconomic reality of Country, to the complex matter of schooling and school dropouts. This was possible thanks to the program of the Social Pediatrics Course (FMRP-USP), which allowed for the undertaking of an articulation with the purpose of the Nucleus for the Study of Children and Adolescents and of the Science Teaching Laboratory at (FFCL-USP).
\end{abstract}

Key words: academic background, conscripts, interdisciplinary, failing, school dropouts

26. BARBIERI, M. R., CARVALHO, C. P. Formação de professores em tempos de informática. Comunicação \& Educação. São Paulo: CCA-ECA-USP/Moderna, n. 9, maio/ago. 1997.

27. BOSI, A. Educação: as coisas e as pessoas. Comunicação \& Educação. São Paulo: CCA-ECA-USP/Moderna, n. 7, set./dez. 1996. p. 13-15. 